\title{
Gypsum-Based Material for Dental Pulp Capping: Effect of Chitosan and BMP-2 on Physical, Mechanical, and Cellular Properties
}

\author{
Hasan Subhi, ${ }^{1}$ Fazal Reza, ${ }^{2}$ Adam Husein, ${ }^{1}$ \\ Saaid Ayesh Al Shehadat, ${ }^{3}$ and Asma-Abdullah Nurul ${ }^{4}{ }^{4}$ \\ ${ }^{1}$ Conservative Dentistry Unit, School of Dental Sciences, Universiti Sains Malaysia, 16150 Kubang Kerian, Kelantan, Malaysia \\ ${ }^{2}$ Biomaterials and Prosthodontics Unit, School of Dental Sciences, Universiti Sains Malaysia, 16150 Kubang Kerian, Kelantan, Malaysia \\ ${ }^{3}$ Department of Prevention and Restorative Dentistry, College of Dental Medicine, University of Sharjah, Sharjah, UAE \\ ${ }^{4}$ School of Health Sciences, Universiti Sains Malaysia, 16150 Kubang Kerian, Kelantan, Malaysia \\ Correspondence should be addressed to Asma-Abdullah Nurul; nurulasma@usm.my
}

Received 3 May 2018; Accepted 2 July 2018; Published 26 July 2018

Academic Editor: Rosalind Labow

Copyright (C) 2018 Hasan Subhi et al. This is an open access article distributed under the Creative Commons Attribution License, which permits unrestricted use, distribution, and reproduction in any medium, provided the original work is properly cited.

\begin{abstract}
Effective pulp capping material must be biocompatible and have the ability to induce dentin bridge formation as well as having suitable physical and mechanical properties; however, many current materials do not satisfy the clinical requirements. This study aimed to assess the physical and mechanical properties of gypsum-based chitosan material (Gp-CT) and to evaluate its effects on cellular properties of stem cells from human exfoliated deciduous teeth (SHED). The experimental material was prepared with different concentrations of chitosan (CT) with or without BMP-2. Then, setting time, compressive strength, and $\mathrm{pH}$ were determined. In addition, cell viability, alkaline phosphatase (ALP) activity, and cell attachment were assessed. The setting time, compressive strength, and $\mathrm{pH}$ obtained were 4.1-6.6 $\mathrm{min}, 2.63-5.83 \mathrm{MPa}$, and 6.5-5.7, respectively. The cell viability to gypsum (Gp) with different CT concentrations was similar to that of the control on day 1 but statistically different from that of Gp alone on day 3. The ALP activity of SHED was significantly higher $(\mathrm{p}<0.05)$ in CT- and BMP-2-containing materials than those in the control and Dycal at days 3 and 14. The scanning electron microscopy (SEM) image revealed that flattened cells were distributed across and adhered to the material surface. In conclusion, Gp-CT material shows promise as a potential material for direct pulp capping.
\end{abstract}

\section{Introduction}

Direct pulp capping is a process of covering the exposed vital pulp with a material to maintain its vitality and preserve its biological and functional activities. The capping material is applied to the exposed site to induce the formation of reparative dentin. Effective pulp capping materials must be biocompatible and have the ability to induce dentin bridge formation; however, many current materials do not satisfy the clinical requirements.

A number of pulp capping materials have been introduced. Calcium hydroxide was the material of choice for pulp capping because of its ability to stimulate hard-tissue deposition and high antibacterial efficiency [1]. However, this compound exhibits several limitations, such as poor sealing, formation of "tunnel defects" in dentin barrier, and gradual degradation [2-4]. Calcium silicate-based materials, such as mineral trioxide aggregate (MTA), and Biodentine have been used in pulp capping. MTA is a suitable material for pulp capping, demonstrating a higher success rate than calcium hydroxide [5]. MTA is superior to conventional pulp capping materials but exhibits poor handling properties, high cost, and slow setting time [6-8].

Studies on material development have progressed. Bioinspired materials are being developed to preserve and induce the regeneration at the application site. Calcium sulfate or "gypsum" is widely used in dentistry and orthopedics because of its biocompatibility [9]. Gp can be utilized as a 
resorbable scaffold to support bone growth and release drugs associated with graft materials [10]. Numerous studies have investigated the effects of CT-incorporated Gp compound in tissue regeneration; this compound exhibits biocompatibility and stimulates osteogenesis/odontogenesis and is thus studied for bone formation in orthopedics [11-13] and as a pulp capping material in dentistry $[14,15]$. It promotes osteoinduction and bone formation when incorporated with bone morphogenetic protein-2 (BMP-2) [16, 17]. Therefore, in the present study we evaluated the potential of Gp-CT material with BMP-2 for direct pulp capping.

This study aimed to determine the setting time, compressive strength, and $\mathrm{pH}$ of an experimental Gp-CT and to evaluate its effects on cell viability, ALP activity, and cell attachment when incorporated with BMP-2 and compare the material with Dycal.

\section{Materials and Methods}

2.1. Preparation of the Materials. PROTASAN UP CL 113 is a well-characterized water-soluble chitosan chloride referred to as CT in this study (NovaMatrix, Norway; 75\%-90\% degree of deacetylation; molecular weight of 50,000-150,000 $\mathrm{g} / \mathrm{mol}$ ). Calcium sulfate dihydrate (Sigma-Aldrich, India) was heated at $110^{\circ} \mathrm{C}$ for $3 \mathrm{~h}$ in an electric oven (Universal Oven Memmert Life 600, Schwabach, Germany) for conversion into a hemihydrate form $\left(\mathrm{CaSO}_{4} \bullet 1 / 2 \mathrm{H}_{2} \mathrm{O}\right)$ [14]. BMP-2 was subjected to ALP assay and SEM to evaluate its effects on SHED.

BMP-2 (AllCells, USA) was impregnated in distilled water to obtain a concentration of $50 \mathrm{ng} / \mathrm{ml}$ and form BMP-2 solution. CT powder was then added and dissolved to prepare five different concentrations of CT solution of $10 \%, 5 \%, 2.5 \%$, $1 \%$, and $0 \% \mathrm{w} / \mathrm{v}$. Gp was mixed with the CT solutions to prepare the material. The ratio of CT solution to Gp is $0.6 \mathrm{ml} / \mathrm{g}$. Dycal (DENTSPLY Caulk, USA) was prepared in accordance with the manufacturers' instructions.

2.2. Setting Time. Molds with a diameter of $10 \mathrm{~mm}$ and a height of $5 \mathrm{~mm}$ were filled with freshly mixed experimental materials and Dycal. The samples were then stored at $37 \pm 1^{\circ} \mathrm{C}$ and at relative humidity of at least $95 \%$. A Vicat needle with $300 \mathrm{~g}$ in weight and a needle having a flat ended cylindrical tip of $1.0 \pm 0.02 \mathrm{~mm}$ in diameter was applied carefully to the surface of the sample and indentations were made at 15 sec intervals in new locations. The setting time was recorded from the start of mixing to the nearest $15 \mathrm{sec}$ interval at which the needle failed to penetrate the sample completely. Six samples of each tested material were evaluated. The average of the individual trials was examined.

2.3. Compressive Strength. The materials and Dycal were mixed, placed in molds with a diameter of $6 \mathrm{~mm}$ and a height of $12 \mathrm{~mm}$, and stored at $37^{\circ} \mathrm{C}$ for $24 \mathrm{~h}$. The molds were then removed, and the specimens were placed between the platens of a universal testing machine (Instron 8874, USA). The load was applied along the long axis of the specimens at a crosshead speed of $1 \mathrm{~mm} / \mathrm{min}$. The compressive strength was recorded at the point of the specimen fracture. Six samples of each material were evaluated. The compressive strength was calculated in megapascals according to

$$
\mathrm{C}=\frac{4 \mathrm{P}}{\pi \mathrm{D}^{2}}
$$

$\mathrm{P}$ is the maximum load applied in Newton.

$\mathrm{D}$ is the mean diameter of the specimen in millimeters.

2.4. $p H$ Value. The materials and Dycal were mixed and placed into plastic wells at approximately $10 \mathrm{~mm}$ in diameter and $5 \mathrm{~mm}$ deep. A digital $\mathrm{pH}$ meter (FieldScout SoilStik, Spectrum Technologies, Inc., China) was used to measure the $\mathrm{pH}$ levels. A small amount of distilled water was dispensed to wet the surface of the materials before the electrode was placed onto the surface of the set material.

The $\mathrm{pH}$ measurements of the materials were recorded at $10 \mathrm{~min}, 2 \mathrm{~h}$, and $24 \mathrm{~h}$. Prior to measurements, the device was calibrated using buffer solutions with $\mathrm{pH} 4$ and 7 throughout the experiment. Six measurements for each material were recorded for analysis.

2.5. Culture of Stem Cells from Human Exfoliated Deciduous Teeth. SHED were purchased from AllCells, USA. The cells at passage 8 were cultured in Alpha minimum essential medium [ $\alpha$-MEM; Invitrogen, USA (GIBCO)] supplemented with $10 \%$ fetal bovine serum [FBS; Invitrogen, USA (GIBCO)] and $1 \%$ penicillin-streptomycin solution [Invitrogen, USA (GIBCO)]. The cells were incubated in a humidified incubator with $\mathrm{CO}_{2}$ at $37^{\circ} \mathrm{C}$.

2.6. MTS Assay. SHED were seeded in 24-well plates (Nunc ${ }^{\mathrm{TM}}$, Denmark) at $1 \times 10^{4}$ cells $/ 800 \mu$ l of growth medium in each well and incubated for $24 \mathrm{~h}$ at $37^{\circ} \mathrm{C}$ in $5 \% \mathrm{CO}_{2}$. The freshly mixed materials and Dycal were placed in acrylic molds with a diameter of $5 \mathrm{~mm}$ and a height of $3 \mathrm{~mm}$ to fabricate the material discs. After the materials were set, the material discs were released and sterilized with UV light in a biosafety cabinet (Labconco, USA) for $30 \mathrm{~min}$ (15 min for each side).

Afterward, the material discs were placed in the wells under aseptic conditions as described previously [18]. SHED alone served as a control group. Cell viability was evaluated through a 3-(4,5-dimethyl-thiazol-2-yl)-5-(3-carboxy-methoxy-phenyl)-2-(4-sulpho-phenyl)-2H tetrazolium assay. On days 1 and 3, the material discs and the culture medium were removed. Afterward, $300 \mu$ l of culture medium and $60 \mu \mathrm{l}$ of MTS (Promega, USA) were added to each well and incubated for $2 \mathrm{~h}$. Then, $100 \mu \mathrm{l}$ of MTS solution from each well was transferred into 96-well plate in triplicate for each material. Absorbance was measured using ELISA reader (Tecan, Japan) at a wavelength of $490 \mathrm{~nm}$. The cell viability was calculated according to

$$
\text { Cell viability }(\%)=\frac{\text { absorbance of samples }}{\text { absorbance of control }} \times 100
$$


2.7. Alkaline Phosphatase Activity. ALP activity was evaluated using a colorimetric ALP assay (Randox, UK). In this procedure, the substrate $p$-nitrophenyl phosphate is hydrolyzed by alkaline phosphatase from the cells in the presence of magnesium ions to form $p$-nitrophenol and finally measured at $405 \mathrm{~nm}$.

SHED at a concentration of $\left(2.5 \times 10^{4}\right.$ cells $/ 1 \mathrm{~mL}$ of medium per well) were cultured in a 12 -well plate and incubated at $37^{\circ} \mathrm{C}$ in $5 \% \mathrm{CO}_{2}$ for $24 \mathrm{~h}$. The material disc as prepared in MTS assay of two groups with or without BMP-2 incorporation was placed in each well. SHED alone served as a control group, and the culture medium was changed every 3 days. At 3 and 14 days of incubation, the material discs were removed, and $100 \mu \mathrm{l}$ of the supernatant was transferred into a new 96-well plate in quadruplicate for each material. Afterward, $15 \mu \mathrm{l}$ of the ALP substrate pNPP was added to each well and incubated for $1 \mathrm{~h}$ in an incubator with $5 \% \mathrm{CO}_{2}$. Then, $20 \mu \mathrm{l}$ of $1 \mathrm{M}(\mathrm{NaOH})$ stop solution was added, and the absorbance was measured using ELISA reader at $405 \mathrm{~nm}$.

2.8. Scanning Electron Microscopy. The material discs with a diameter of $12 \mathrm{~mm}$ and a height of $2 \mathrm{~mm}$ were placed in a 24 -well plate. SHED were then seeded at $5 \times 10^{4}$ cells on the materials discs and immersed in the medium. The plates were incubated for 3 days at $37^{\circ} \mathrm{C}$ in $5 \% \mathrm{CO}_{2}$. The material discs were washed with distilled water and fixed with $2.5 \%$ glutaraldehyde for $2 \mathrm{~h}$ at $4^{\circ} \mathrm{C}$. Then, the samples were dehydrated in ethanol at the concentrations of $30 \%, 50 \%, 70 \%, 80 \%$, $90 \%$, and $100 \%$ for $10 \mathrm{~min}$ at each concentration and later dried in a desiccator (FSD-380, TECH-LAB SCIENTIFIC, Malaysia). Finally, the samples were sputter coated with gold and examined under SEM (Phenom-World, Netherland).

2.9. Statistical Analysis. Statistical analyses were performed using SPSS (Version 22.0; SPSS, Chicago, IL). Statistical significance was evaluated by one-way analysis of variance (ANOVA) followed by Dunnett T3 post hoc test for multiple comparisons in setting time, compressive strength, MTS assay, and ALP activity. Statistical analysis of the $\mathrm{pH}$ values was performed by repeated measures analysis of variance (ANOVA). A value of $\mathrm{p}<0.05$ was considered statistically significant.

\section{Results}

3.1. Setting Time. The setting time of the materials and Dycal is listed in Figure 1. The setting time of the experimental materials ranged from $4.1 \mathrm{~min}$ to $6.6 \mathrm{~min}$; the setting time was longer in the higher CT concentration. This result indicated that setting time was altered in a dose-dependent manner. Our findings further showed that setting time of Gp-5\%CT and Gp-10\%CT was significantly longer than Gp- $0 \% \mathrm{CT}$ (p < 0.05 ). Dycal showed a setting time of $1.5 \mathrm{~min}$, and this result significantly differed from the setting time of all the tested materials $(\mathrm{p}<0.05)$.

3.2. Compressive Strength. The compressive strength of the materials and Dycal is listed in Figure 2. The compressive

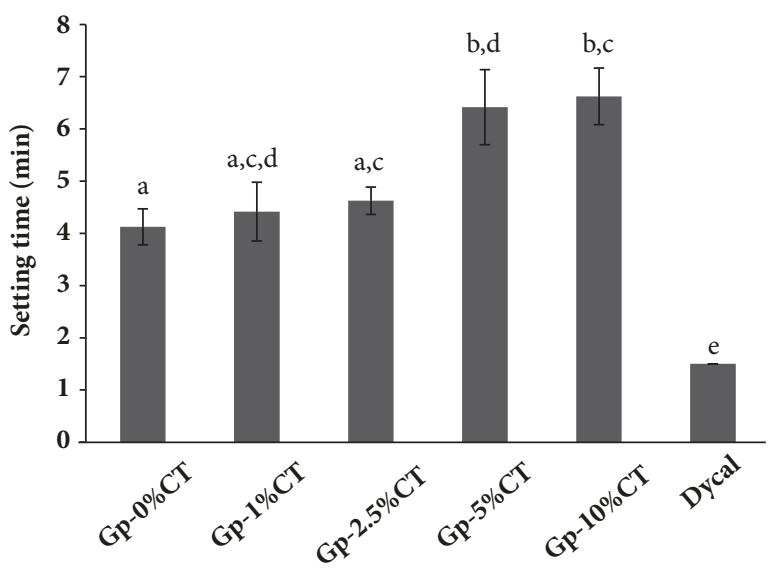

FIGURE 1: The setting time of Gp-CT materials and Dycal. The error bars represent the standard deviation. Bars with different letters are statistically significant at $\mathrm{p}<0.05$.

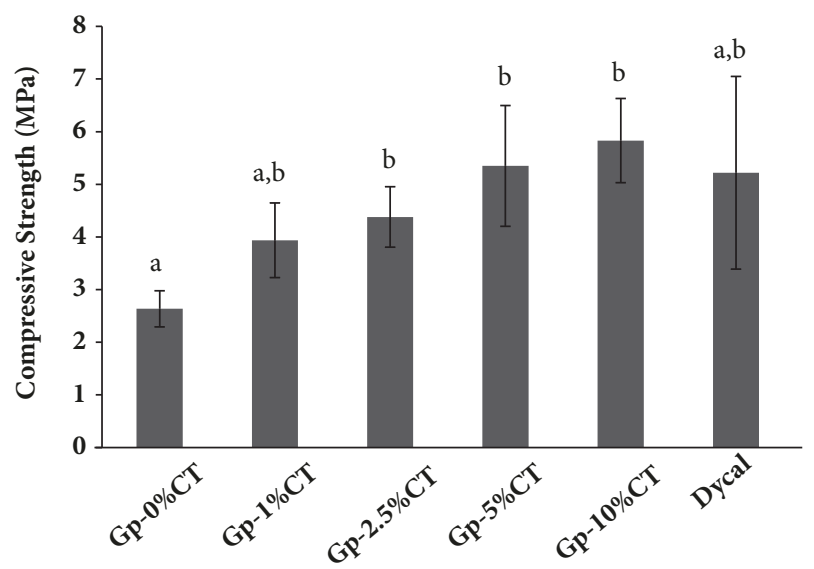

Figure 2: Compressive strength of the Gp-CT materials and Dycal. The error bars represent the standard deviation. Bars with different letters are statistically significant at $\mathrm{p}<0.05$.

strength of the experimental materials ranged from 2.63 $\mathrm{MPa}$ to $5.83 \mathrm{MPa}$. Results indicated that a high compressive strength corresponded to higher CT concentration. Compressive strength of Gp-2.5\%CT, Gp-5\%CT, and Gp$10 \% \mathrm{CT}$ was significantly higher than $\mathrm{Gp}-0 \% \mathrm{CT}$. Interestingly, compressive strength of Gp-5\%CT and Gp-10\%CT was comparable with that of Dycal.

3.3. $\mathrm{PH}$ Value. The $\mathrm{pH}$ of the materials and Dycal is listed in Figure 3 . The $\mathrm{pH}$ of the $\mathrm{Gp}-\mathrm{CT}$ materials at $24 \mathrm{~h}$ ranged from 6.5 to 5.7, with a tendency toward lower $\mathrm{pH}$ with higher CT concentration. Similar tendency was observed at $10 \mathrm{~min}$ with slightly higher $\mathrm{pH}$ than that of $24 \mathrm{~h}$ while consistently high alkaline $\mathrm{pH}$ of approximately 12.5 was observed with Dycal at $24 \mathrm{~h}$ with significant differences with the measurement at 10 $\min$.

3.4. MTS Assay. Figures 4(a) and 4(b) show the viability of the SHED treated with the experimental material and Dycal. On day 1 , the cell viability of the experimental materials 


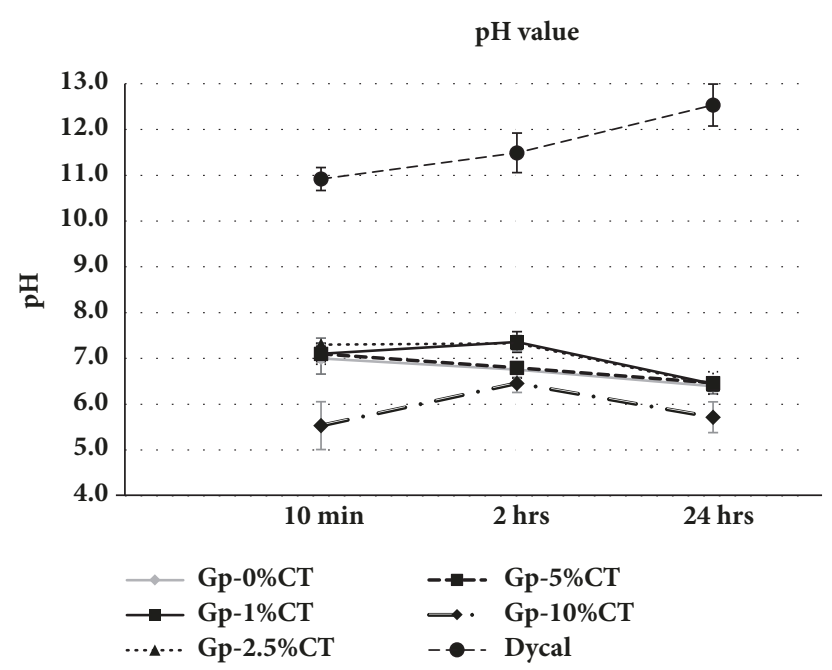

FIgURE 3: $\mathrm{pH}$ values of Gp-CT materials and Dycal at $10 \mathrm{~min}, 2 \mathrm{hrs}$, and 24 hrs $($ mean $\pm \mathrm{SD})$.

ranged from $98.5 \%$ to $111.9 \%$. There was no significant difference of the viability from the cells cultured on experimental materials compared to the control group at day 1 . However, cell viability of the experimental materials showed decreasing pattern at day 3. Interestingly, SHED cultured with Gp-CT showed higher viability compared to Gp alone. In contrast, Dycal demonstrated cytotoxic effects to the SHED with the cell viabilities of $28 \%$ and $14.2 \%$ on days 1 and 3 , respectively, and the viability was significantly lower than all the materials and the control $(\mathrm{p}<0.05)$.

3.5. Alkaline Phosphatase Activity. The ALP activity of the SHED cultured with the material and Dycal is shown in Figures 5(a) and 5(b). On day 3, SHED cultured with the experimental materials showed statistically higher ALP activity than the control groups and Dycal $(\mathrm{p}<0.001)$. No significant differences could be noted in the ALP activities of $\mathrm{Gp}-\mathrm{CT}$ (at various concentrations) prepared in the presence of BMP-2 when compared with Gp-CT without BMP-2.

On day 14, SHED seeded on various concentrations of Gp-CT with or without BMP-2 demonstrated significantly higher ALP activity than the control group and Dycal. SHED seeded on Gp-CT-BMP with various CT concentrations showed higher ALP activity than those on Gp-0\%CT-BMP. In addition, Gp-1\%CT-BMP exhibited significantly lower ALP activity than Gp-2.5\%CT-BMP, Gp-5\%CT-BMP, and Gp10\%CT-BMP. Interestingly, Gp-2.5\%CT-BMP demonstrated significantly higher ALP activity than Gp-2.5\%CT alone ( $\mathrm{p}=$ 0.016).

3.6. Scanning Electron Microscopic Analysis. Results revealed that flattened SHED spread across the surface and adhered to the underlying material through their cytoplasmic processes. Multiple thin cytoplasmic extensions were extended from the cells and projected to the surrounding adjacent cell surface (Figures 6(A)-6(E)). By contrast, few rounded cells were observed on Dycal (Figure 6(F)).

\section{Discussion}

Direct pulp capping is important to avoid more invasive and resource-intensive procedures of conventional root canal treatment. It initiates the formation of dentin by reparative dentinogenesis through a series of processes that begin with the differentiation of dental pulp stem cells into odontoblastlike cells. Growth factors, such as BMP-2, play an important role in dentin regeneration and dentinogenesis [19]. The ability of pulp capping materials to induce SHED differentiation is critical and is mainly determined by interactions between the materials and cells. SHED provide an eligible cell source for regenerative endodontics because these cells originate from dental tissues and differentiate successfully into odontoblast-like cells [20].

Results showed that the setting time increased with increasing CT concentration, indicating dose-dependent changes. That may be related to the high viscosity of the CT-containing solution of materials, resulting in obstruction of ion diffusion in the matrix [21]. The setting time of Gp-CT meets the guideline of ISO 3107 guideline for zinc oxide/eugenol cements and zinc oxide/noneugenol which recommends a setting time range of 4-10 $\mathrm{min}$ [22].

The mechanical properties of $\mathrm{Gp}$ can be affected by the compression in microstructure and size (thickness and length) of the entangled crystals [23]. The compressive strength increased with increasing CT concentration. A high CT concentration yields a highly viscous CT solution, which reduces the porosity of hardened materials [24] and also influences Gp crystallization by producing thick and protracted crystals of tightly locked Gp-CT materials [14]. Similarly, Ślósarczyk et al. [24] have stated that the compressive strength of the cement is influenced by the concentration of CT solution added.

The $\mathrm{pH}$ of Gp-CT after $24 \mathrm{~h}$ ranged from 6.5 to 5.7 , and a lower $\mathrm{pH}$ was obtained when using higher $\mathrm{CT}$ concentration (Gp-10\%CT). The $\mathrm{pH}$ values recorded are considered suitable for pulp capping because they are ideal for cell culture [25] and may form a necrotic zone-free area on the application site.

The cell viability was enhanced when $\mathrm{CT}$ added to the material. Compared to the control, Gp-CT demonstrated no cytotoxic effects, and an enhanced cell viability to Gp$2.5 \% \mathrm{CT}, \mathrm{Gp}-5 \% \mathrm{CT}$, and $\mathrm{Gp}-10 \% \mathrm{CT}$ was observed on day 1 , while a significantly declined cell viability was reported on day 3. The percentage of cell viability in treatment with $\mathrm{Gp}-0 \% \mathrm{CT}$ decreased to $61.3 \%$ on day 3, indicating the lowest cell viability. Gp is an osteoinductive and passiveosteoconductive material because of its unique crystal structure and high calcium content [26]. Takita et al. [25] have stated that calcium-containing elution increases the proliferation of human dental pulp cells in dose-dependent manner. By contrast, Dycal induced high cytotoxicity to the cells, similar to the previous findings $[27,28]$; the high cytotoxicity of Dycal is related to the high $\mathrm{pH}$.

SHED cultured with various concentrations of Gp-CT with or without BMP-2 demonstrated higher ALP activity than the control and Dycal on days 3 and 14. Gp2.5\%CT incorporated with BMP-2 yielded a higher ALP 


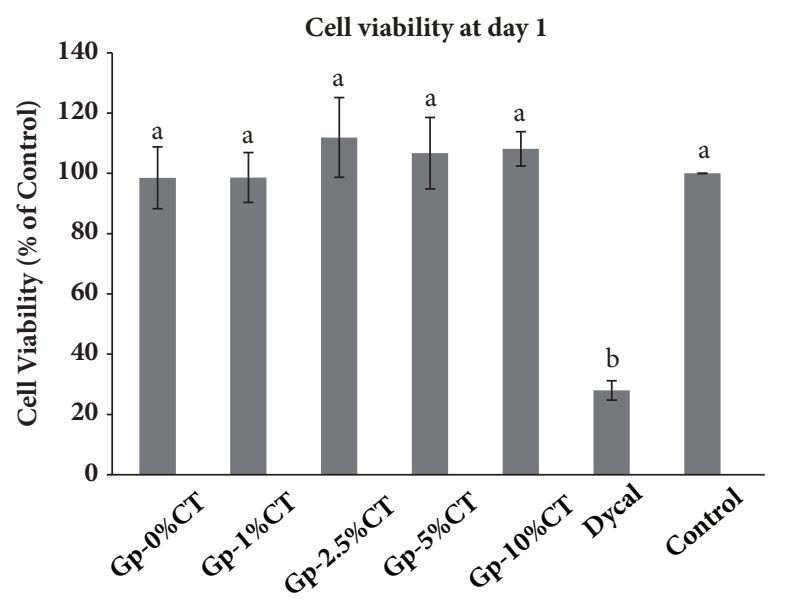

(a)

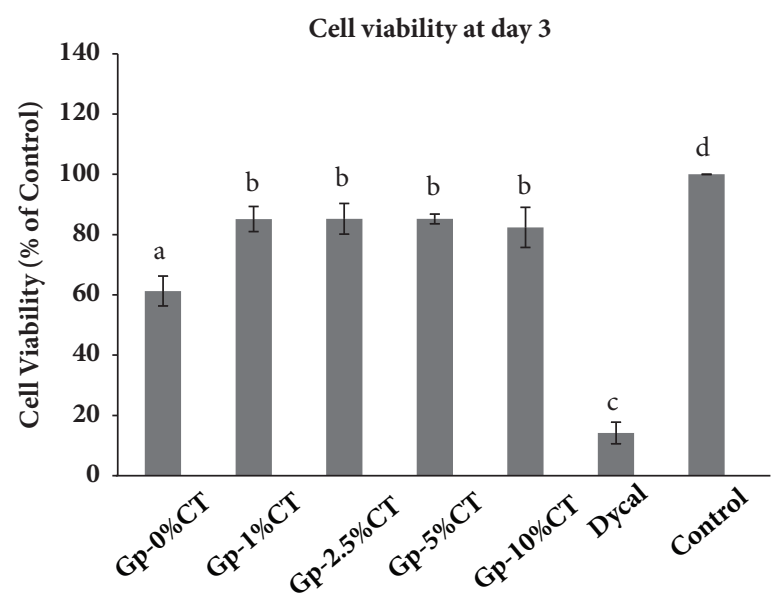

(b)

FIGURE 4: Cell viability values of SHED cultured with various concentrations of Gp-CT and Dycal after (a) 1 day and (b) 3 days as measured by MTS assay. The error bars represent the standard deviation. Bars with different letters are statistically significant at $\mathrm{p}<0.05$.

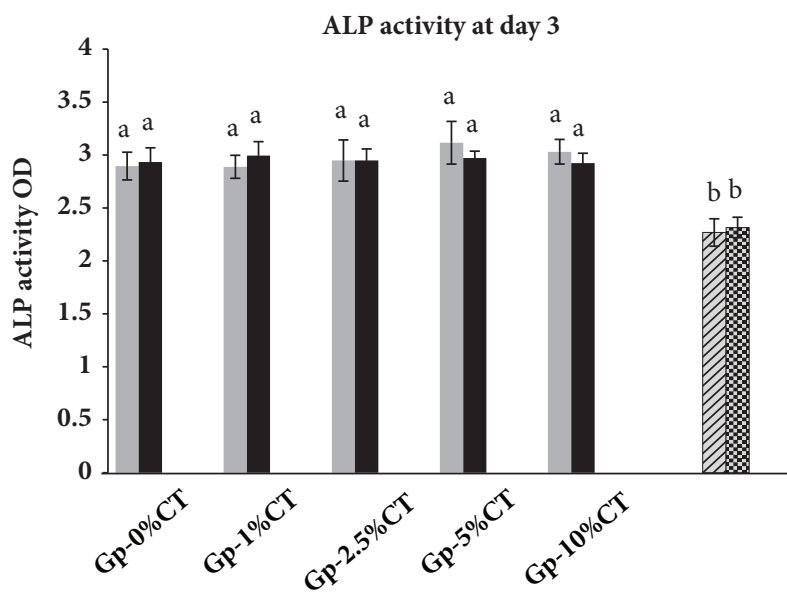

(a)

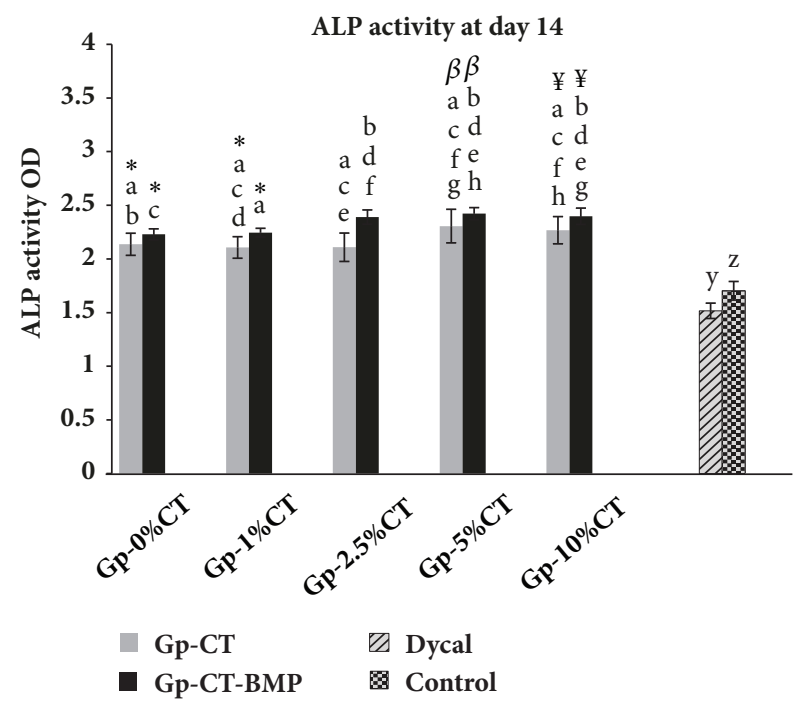

(b)

FIgure 5: ALP activity of the Gp-CT and Dycal on SHED after (a) 3 days and (b) 14 days of incubation. The Gp-CT was cultured with or without BMP-2. The error bars represent the standard deviation. Bars with different letters are statistically significant at $\mathrm{p}<0.05$.

activity on day 14 when compared to Gp-2.5\%CT alone. The experimental material enhanced the concentration of ALP released outside the cells; this finding may be attributed to the influence of the experimental material on the osteogenic differentiation of the cells. Similarly, Lisa et al. [29] evaluated the potential of CT to induce osteogenic differentiation of macaque dental pulp stem cells and revealed that CT possibly promoted the release of ALP into the medium. Calcium sulfate provides a source of calcium ions, which accelerates the mineralization and regeneration of the tissue [30]. In addition, the enhancement of ALP activity by CT was reported in many studies [29,31].
The cells were apparently healthy under SEM after 3 days of seeding on the material surface. The cells spread and adhered to the materials at all CT concentrations. Cell adhesion is implicated in cell growth, differentiation, and proliferation; this complicated process is also involved in wound healing [32]. The cells appeared flat and exhibited well-defined cytoplasmic extensions. The presence of cytoplasmic extensions is necessary to form three-dimensional networks inside the materials. Lazáry et al. [26] have found that osteoblasts adhered to the surface of Gp because of its physical structure. Moreover, Gp contains a number of small crystals located side by side; these crystals form a large 


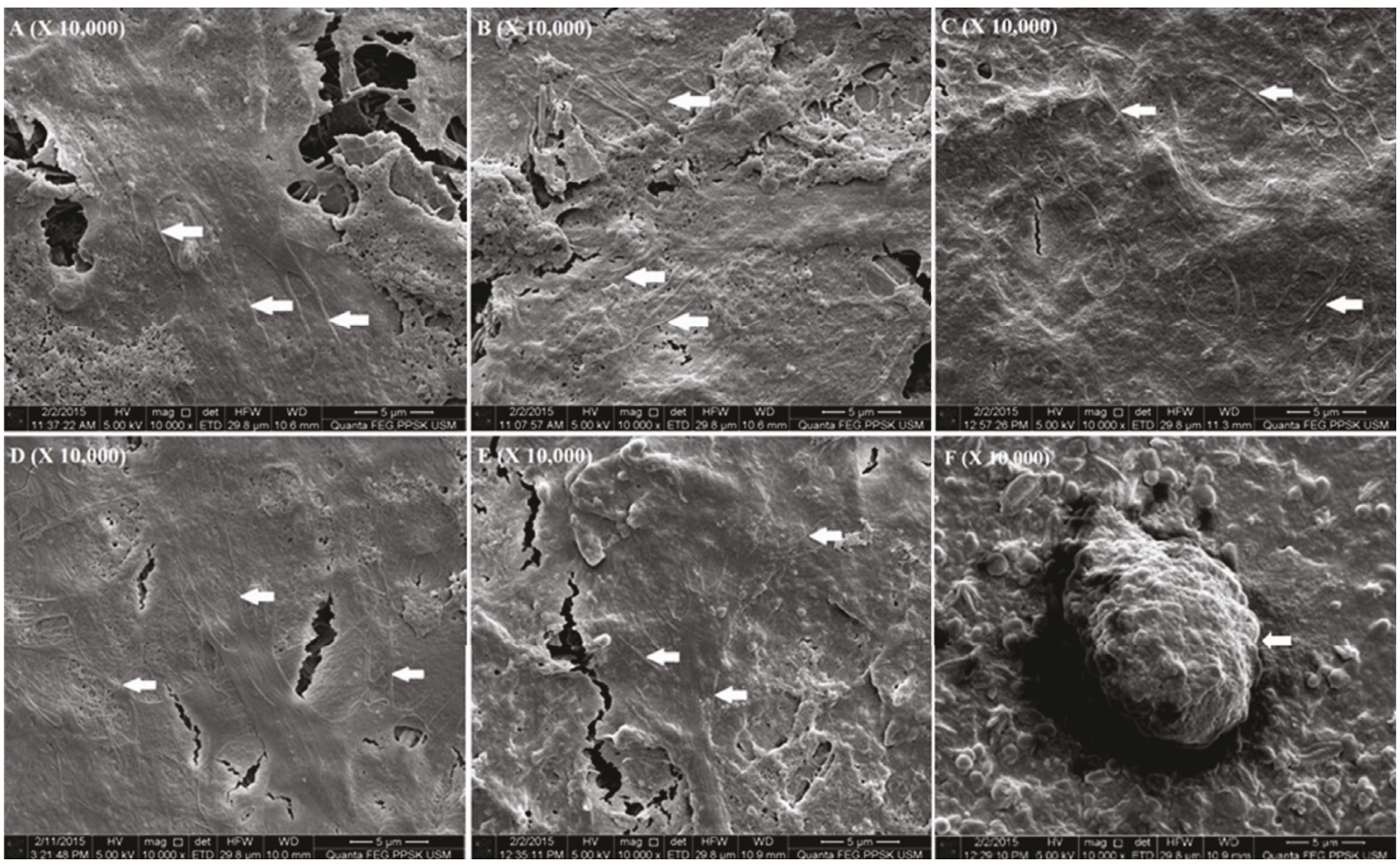

FIGURE 6: SEM analysis of SHED attachment and growth following 3 days of incubation on (A) Gp-0\%CT-BMP material, (B) Gp-1\%CT-BMP material, (C) Gp-2.5\%CT-BMP material, (D) Gp-5\%CT-BMP material, and (E) Gp-10\%CT-BMP material. Pictures showing numerous thin cytoplasmic extensions of the cells (white arrows); (F) SEM analysis showing rounded nonliving cell on Dycal (white arrows).

molecular surface. By contrast, few rounded and detached cells were distributed on the surface of Dycal. These cells are dead and comparable with those described in a previous study [33].

\section{Conclusions}

The results of our study showed that Gp-CT material demonstrated acceptable setting time and compressive strength for clinical applications and also stable $\mathrm{pH}$ values. In addition, the material demonstrated a potential to promote the proliferation, differentiation, and attachment of SHED in vitro. However, the mechanism through which Gp-CT stimulates the osteogenic/odontogenic differentiation of SHED should be further investigated.

\section{Data Availability}

The mean \pm SD data in excel file used to support the findings of this study are available from the corresponding author upon request.

\section{Conflicts of Interest}

The authors declare that there are no conflicts of interest regarding the publication of this article.

\section{Acknowledgments}

The authors would like to thank the staffs of Craniofacial Science Laboratory, School of Dental Sciences, Universiti Sains Malaysia, for their technical supports. This study was supported by short term grants [no. 304/PPSG/61313006 and no. 304/PPSG/61312099] of Universiti Sains Malaysia.

\section{References}

[1] Z. Mohammadi and P. M. H. Dummer, "Properties and applications of calcium hydroxide in endodontics and dental traumatology," International Endodontic Journal, vol. 44, no. 8, pp. 697-730, 2011.

[2] J. L. Ferracane, Materials in Dentistry: Principles and Applications, Lippincott Williams \& Wilkins, Philadelphia, Pa, USA, 2nd edition, 2001.

[3] C. F. Cox, R. K. Sübay, E. Ostro, S. Suzuki, and S. H. Suzuki, "Tunnel defects in dentin bridges: their formation following direct pulp capping," Operative Dentistry, vol. 21, no. 1, pp. 411, 1996.

[4] A. H. B. Schuurs, R. J. M. Gruythuysen, and P. R. Wesselink, "Pulp capping with adhesive resin-based composite vs. calcium hydroxide: a review," Dental Traumatology, vol. 16, no. 6, pp. 240-250, 2000.

[5] T. Okiji and K. Yoshiba, "Reparative Dentinogenesis Induced by Mineral Trioxide Aggregate: A Review from the Biological and Physicochemical Points of View," International Journal of Dentistry, vol. 2009, pp. 1-12, 2009. 
[6] T. J. Hilton, "Keys to Clinical Success with Pulp Capping: A Review of the Literature," Operative Dentistry, vol. 34, no. 5, pp. 615-625, 2009.

[7] B. S. Ber, J. F. Hatton, and G. P. Stewart, "Chemical modification of proroot MTA to improve handling characteristics and decrease setting time," Journal of Endodontics, vol. 33, no. 10, pp. 1231-1234, 2007.

[8] I. Islam, H. K. Chng, and A. U. Jin Yap, "Comparison of the physical and mechanical properties of MTA and portland cement," Journal of Endodontics, vol. 32, no. 3, pp. 193-197, 2006.

[9] M. V. Thomas, D. A. Puleo, and M. Al-Sabbagh, "Calcium sulfate: A review," Journal of Long-Term Effects of Medical Implants, vol. 15, no. 6, pp. 599-607, 2005.

[10] M. V. Thomas and D. A. Puleo, "Calcium sulfate: properties and clinical applications," Journal of Biomedical Materials Research Part B: Applied Biomaterials, vol. 88, no. 2, pp. 597-610, 2009.

[11] B. C. Cho, J. W. Park, B. S. Baik, I. C. Kwon, and I. S. Kim, "The role of hyaluronic acid, chitosan, and calcium sulfate and their combined effect on early bony consolidation in distraction osteogenesis of a canine model," The Journal of Craniofacial Surgery, vol. 13, no. 6, pp. 783-793, 2002.

[12] G. G. D’Ayala, A. De Rosa, P. Laurienzo, and M. Malinconico, "Development of a new calcium sulphate-based composite using alginate and chemically modified chitosan for bone regeneration," Journal of Biomedical Materials Research Part A, vol. 81, no. 4, pp. 811-820, 2007.

[13] S.-M. Kuo, G. Niu, C.-W. Lan, M.-F. Cheng, M.-Y. Chiang, and S.-J. Chang, "Guided tissue regeneration with use of CaSO4-chitosan composite membrane," Journal of Medical and Biological Engineering, vol. 29, pp. 304-310, 2009.

[14] A. Low, H. Mohd Yusof, F. Reza et al., "Gypsum-based biomaterials: Evaluation of physical and mechanical properties, cellular effects and its potential as a pulp liner," Dental Materials Journal, vol. 34, no. 4, pp. 522-528, 2015.

[15] H. Subhi, F. Reza, A. Husein, and A. A. Nurul, "Cytotoxicity of gypsum-based biomaterial for direct pulp capping using stem cells from human exfoliated deciduous teeth," Journal of Conservative Dentistry, vol. 21, pp. 21-25, 2018.

[16] H. Chen, X. Cui, X. Yu et al., "Effects of chitosan-coated pressed calcium sulfate pellets combined with recombinant human bone morphogenetic protein 2 on bone formation in femoral condyle-contained bone defects," The Journal of Craniofacial Surgery, vol. 21, no. 1, pp. 188-197, 2010.

[17] X. Cui, B. Zhang, Y. Wang, and Y. Gao, "Effects of chitosancoated pressed calcium sulfate pellet combined with recombinant human bone morphogenetic protein 2 on restoration of segmental bone defect," The Journal of Craniofacial Surgery, vol. 19, no. 2, pp. 459-465, 2008.

[18] C. A. Chaves, C. E. Vergani, D. Thomas et al., "Biological effects of soft denture reline materials on L929 cells in vitro," Journal of Tissue Engineering, vol. 5, Article ID 2041731414540911, 2014.

[19] T. Saito, M. Ogawa, Y. Hata, and K. Bessho, "Acceleration effect of human recombinant bone morphogenetic protein-2 on differentiation of human pulp cells into odontoblasts," Journal of Endodontics, vol. 30, no. 4, pp. 205-208, 2004.

[20] M. M. Cordeiro, Z. Dong, T. Kaneko et al., "Dental pulp tissue engineering with stem cells from exfoliated deciduous teeth," Journal of Endodontics, vol. 34, no. 8, pp. 962-969, 2008.

[21] R. A. Perez, H. Kim, and M. Ginebra, "Polymeric additives to enhance the functional properties of calcium phosphate cements," Journal of Tissue Engineering, vol. 3, no. 1, p. 2041731412439555, 2012.
[22] "ISO 3107: Dentistry, restorative materials. Geneva, Seitzerland: ISO/TC106. International Organization for Standardization," in Proceedings of the ISO 3107: Dentistry, restorative materials. Geneva, Seitzerland: ISO/TC106. International Organization for Standardization, 2004.

[23] A. Pouria, H. Bandegani, M. Pourbaghi-Masouleh, S. Hesaraki, and M. Alizadeh, "Physicochemical properties and cellular responses of strontium-doped gypsum biomaterials," Bioinorganic Chemistry and Applications, vol. 2012, 2012.

[24] A. Ślósarczyk, N. Osypanka, J. Czechowska, Z. Paszkiewicz, and A. Zima, "Influence of liquid phase on physical properties of the new triphasic bone cement," Archives of Materials Science and Engineering, vol. 54, no. 2, pp. 53-59, 2012.

[25] T. Takita, M. Hayashi, O. Takeichi et al., "Effect of mineral trioxide aggregate on proliferation of cultured human dental pulp cells," International Endodontic Journal, vol. 39, no. 5, pp. 415-422, 2006.

[26] Á. Lazáry, B. Balla, J. P. Kósa et al., "Effect of gypsum on proliferation and differentiation of MC3T3-E1 mouse osteoblastic cells," Biomaterials, vol. 28, no. 3, pp. 393-399, 2007.

[27] E. P. Güven, P. N. Taşli, M. E. Yalvac, N. Sofiev, M. B. Kayahan, and F. Sahin, "In vitro comparison of induction capacity and biomineralization ability of mineral trioxide aggregate and a bioceramic root canal sealer," International Endodontic Journal, vol. 46, no. 12, pp. 1173-1182, 2013.

[28] C. Poggio, C. R. Arciola, R. Beltrami et al., "Cytocompatibility and antibacterial properties of capping materials," The Scientific World Journal, vol. 2014, Article ID 181945, 10 pages, 2014.

[29] L. R. Amir, D. F. Suniarti, S. Utami, and B. Abbas, "Chitosan as a potential osteogenic factor compared with dexamethasone in cultured macaque dental pulp stromal cells," Cell and Tissue Research, vol. 358, no. 2, pp. 407-415, 2014.

[30] Y. Yamazaki, S. Oida, Y. Akimoto, and S. Shioda, "Response of the mouse femoral muscle to an implant of a composite of bone morphogenetic protein and plaster of Paris," Clinical Orthopaedics and Related Research, no. 234, pp. 240-249, 1988.

[31] J.-W. Hou, L. Qian, J.-M. Kou, C.-W. Zhang, X.-J. Jia, and W. Tian, "Effect of water-soluble chitosan on the osteoblast function in MC3T3-E1 cells," International Journal of Biological Macromolecules, vol. 72, pp. 1041-1043, 2015.

[32] A. L. Pérez, R. Spears, J. L. Gutmann, and L. A. Opperman, "Osteoblasts and MG-63 osteosarcoma cells behave differently when in contact with ProRoot ${ }^{\mathrm{TM}}$ MTA and White MTA," International Endodontic Journal, vol. 36, no. 8, pp. 564-570, 2003.

[33] E. P. Guven, M. E. Yalvac, F. Sahin, M. M. Yazici, A. A. Rizvanov, and G. Bayirli, "Effect of dental materials calcium hydroxidecontaining cement, mineral trioxide aggregate, and enamel matrix derivative on proliferation and differentiation of human tooth germ stem cells," Journal of Endodontics, vol. 37, no. 5, pp. 650-656, 2011. 


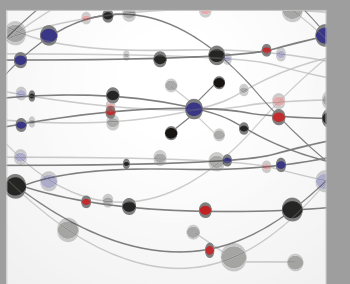

The Scientific World Journal
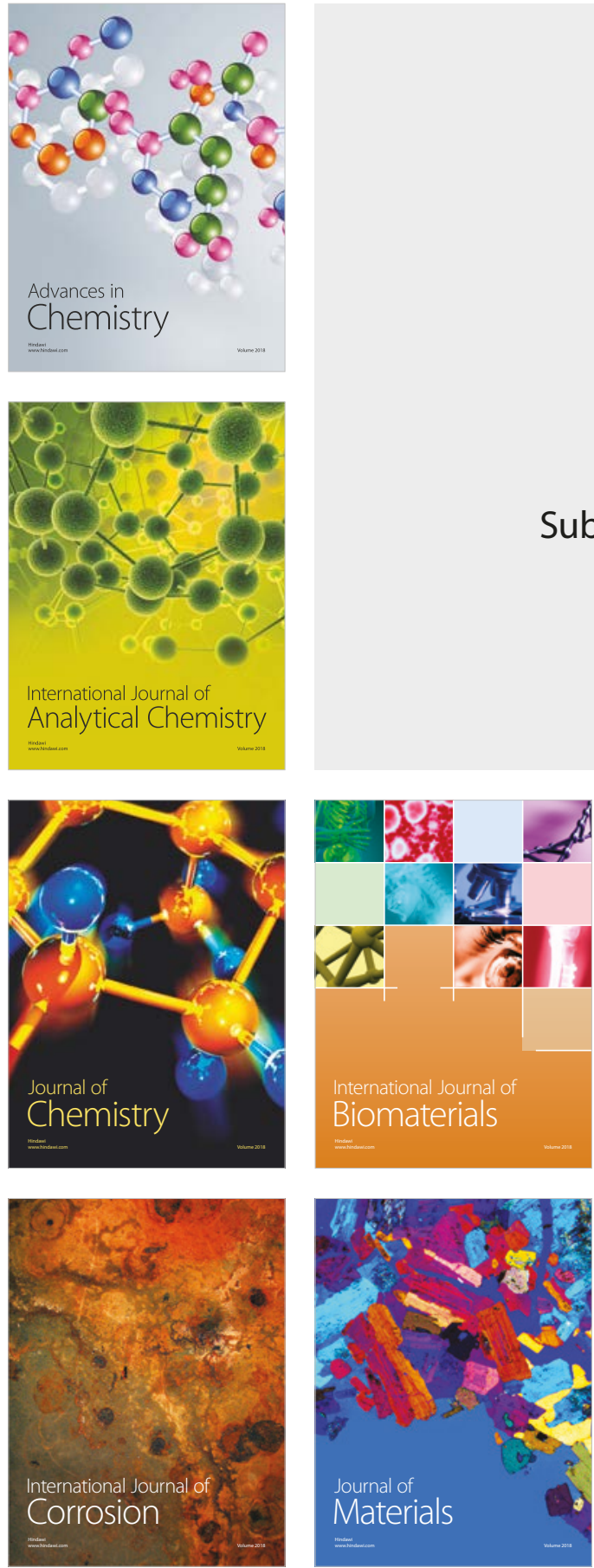

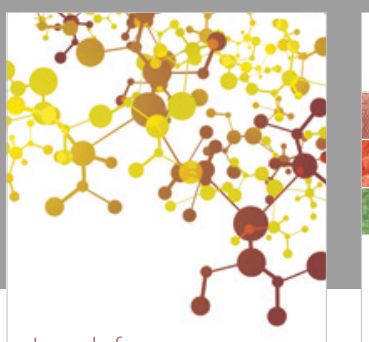

Journal of

Applied Chemistry
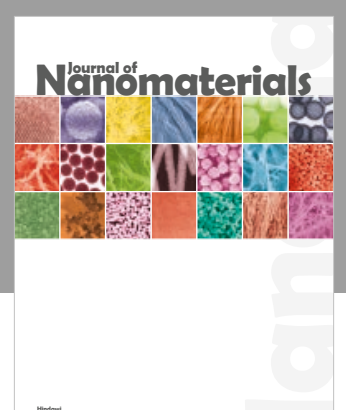

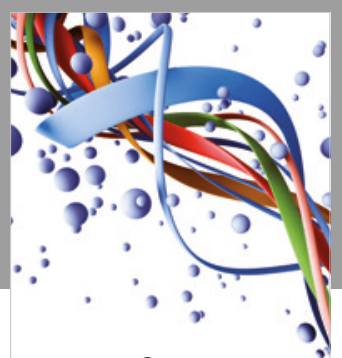

Scientifica

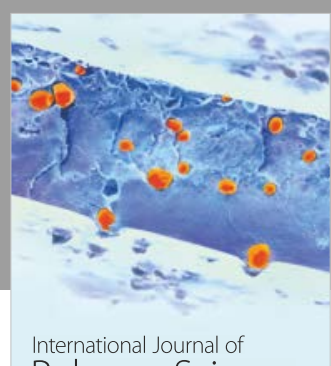

Polymer Science

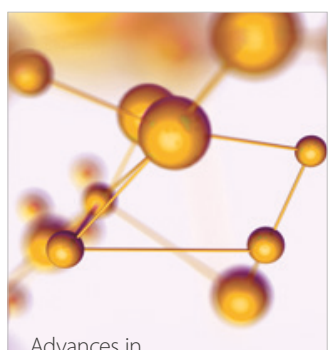

Physical Chemistry
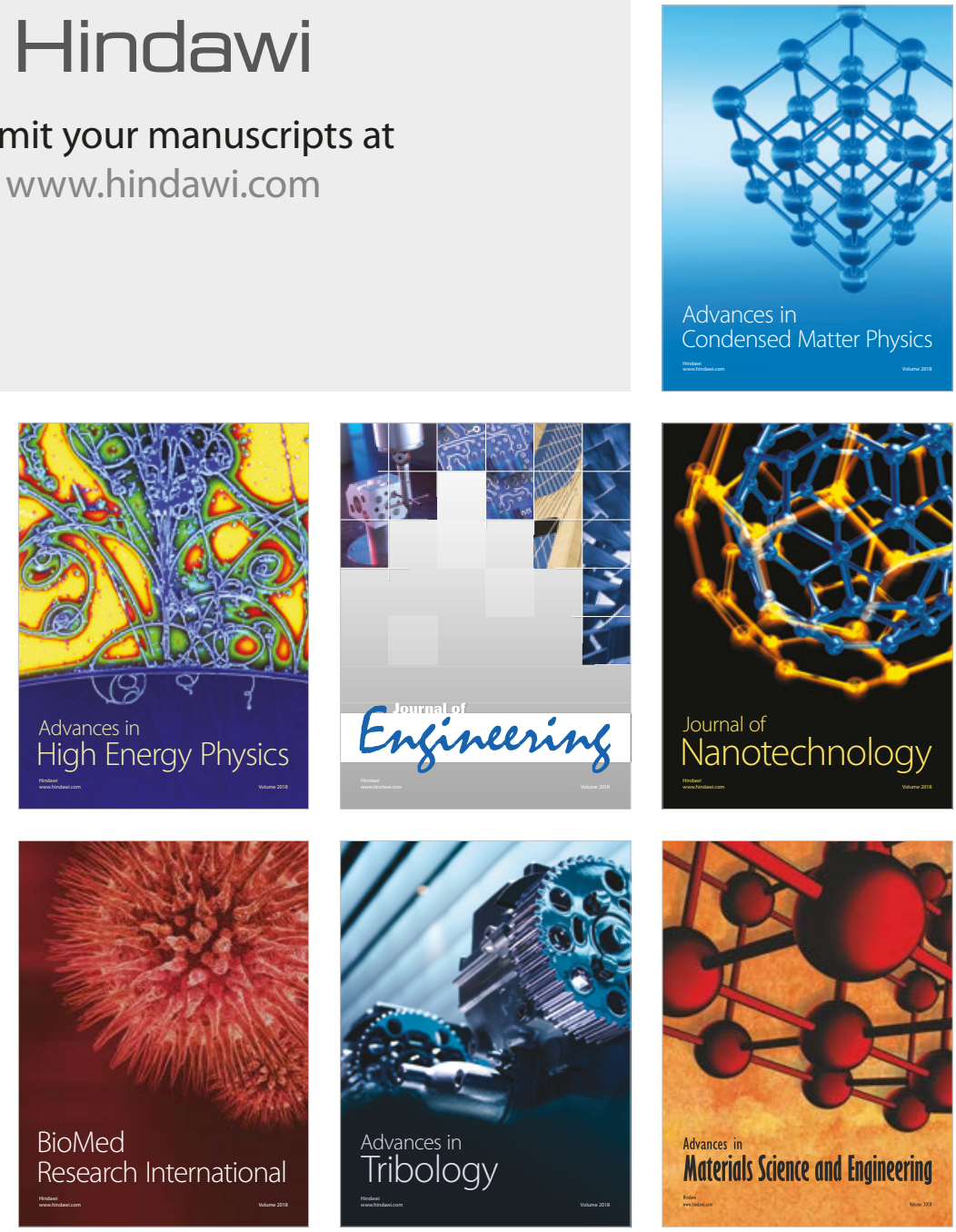